\title{
A Proposed Model for Predicting Employee Turnover of Information Technology Specialists Using Data Mining Techniques
}

\author{
Ahmed Hosny Ghazi \\ Helwan University, \\ Faculty of Commerce \& Business Administration, \\ Department of Business information systems, \\ Cairo, Egypt \\ hosnyghazi@gmail.com

\section{Samir Ismail Elsayed} \\ Helwan University, \\ Faculty of Commerce \& Business Administration, \\ Accounting Department, \\ Cairo, Egypt \\ drsamironline@gmail.com
}

\section{Ayman Elsayed Khedr}

University of Jeddah, College of Computing and Information Technology at Khulais,

Department of Information Systems,

Jeddah, Saudi Arabia

aeelsayed@uj.edu.sa

\begin{abstract}
This article proposes a data mining framework to predict the significant explanations of employee turn-over problems. Using Support vector machine, decision tree, deep learning, random forest, and other classification algorithms, the authors propose features prediction framework to determine the influencing factors of employee turn-over problem. The proposed framework categorizes a set of historical behavior such as years at company, over time, performance rating, years since last promotion, and total working years. The proposed framework also classifies demographics features such as Age, Monthly Income, and Distance from Home, Marital Status, Education, and Gender. It also uses attitudinal employee characteristics to determine the reasons for employee turnover in the information technology sector. It has been found that the monthly rate, overtime, and employee age are the most significant factors which cause employee turnover.
\end{abstract}

Keywords - Data Mining Techniques, Prediction, Classification, Employees satisfactions and turnover

\section{INTRODUCTION}

Despite the efforts made by the organization to develop and improve investments, employee turnover will remain one of the most hazardous challenges facing the organization's return on investments. A lot is spent on employees by the organizations in which they work in terms of orientation, training, development, and maintenance in their organizations. Therefore, managers should at any cost reduce staff turnover [1]. Although there is no specific approach for addressing the Employee attrition problem as a whole, a wide variety of variables have been found to be effective in describing employee turnover. The turnover problem requires more investigating and understanding of causes why employees leave their working organization. The factors that influence employee performance, the consequences, and methods can be placed in place by managers to reduce employee turnover. Organizations must continue to develop tangible products and provide services based on the strategies staff have developed [2].

In any organization, decision-makers should find out the significant factors that might lead to employee turnover in favor of organization sustainability. To find out these factors, managers used different methodologies and techniques. Some managers use interviews and another use questionnaire to determine turn over causes. 
On other hand, some managers use mathematical or statistical models to find out why skillful employees may leave work. Also, decision-makers use some advanced machine learning and classification techniques. The last two approaches are preferable for some decision-makers because they are not biased to human interference. In this research, we will propose a classification model that helps decision-makers to illustrate the most significant factors affecting employee turnover [3].

As the employee turnover problem has not one direct and obvious reason, data mining has been considered a promising approach for information and knowledge discovery [4]. This discovered knowledge can be extracted and accessed through a large amount of data using well define mining algorithms [5]. The data mining approach comprises a set of techniques that can be used to extract relevant information and interesting knowledge from data which might provide a solution to any business problem.

Data mining explores and analyses large blocks of information to glean significant patterns and trends. It can be used in a variety of ways, such as database marketing, credit risk management, fraud detection, spam Email filtering, or even to discern the sentiment or opinion of users. Data mining includes different data analysis techniques such as classification, forecasting, prediction, and clustering [6], [7].

Classification is a supervised learning technique to find hidden patterns using learning by example approach.

Clustering is the process of grouping the data using unsupervised learning techniques such as k-mean, nearest neighbour algorithm and other. On other hand, classification is supervised learning techniques that classify the data element to known labels using different algorithms such as decision tree. Despite the mining technique the main aim is to find the most interested pattern which solve problem [8].

This research paper has been divided into parts. The second part illustrates a set of previous studies that focused on employee turnover reasons prediction using data mining techniques. The third part discusses the proposed model and data pre-processing, experiments, and results that have been achieved. The research summary and conclusions have been presented in the last part.

\section{LITERATURE REVIEW}

A lot of Researchers have been tried to find users' satisfaction reasons in many perspectives such as in [9], [10] and [11]. The following section discussed a number of published articles that illustrate some benefits of datamining techniques in the employee turnover problems briefly.

Classification technique has been used to predict employee performance rates [12],[13]. Their proposed model monitors employee performance, by knowing the most influential attributes, and through the application of classification algorithms. As a conclusion of that research, they found that job title, type, and relatively little impact. The Age attribute showed no obvious effect during the social status. In some of the performed experiments, gender attributes showed some effect on employee performance prediction. Also, Job satisfaction, salary, number of years of experience, and previous companies for each of these attributes have a degree of predictability of performance. In the end, the authors recommended that the model can be used to forecast new employee performance and help make the necessary decisions when hiring new employees to avoid recruiting a poor-performing employee.

Adaptation is one of the key elements in employee satisfaction which has been confirmed in many types of research such as in [14].The classification technique has been used to predict employee attrition rates. The researchers proposed employee attrition models which analyzing employee data to reduce the organization's future losses. The focus of their research was to provide a friendly graphical user interface to facilitate the work of a department of Human resources. They concluded that working experience, age, and technical skills, have the most significant impact on employee turnover. Different methods of data mining have been compared based on their precision, calculation time, and Ease of use [15].

Automated learning algorithms have been used to predict employee turnover factors. The main challenge in their study was noise-filled data from (Human Resource Information System (HRIS) [16]. The authors compared the results of their classifier against six other classifiers. Their proposed classifier has been achieved excellent results in terms of accuracy, time consumption, and memory allocation for predicting attrition. The proposed classifier confirmed that it was effective in solving the problem of data noise than HRIS than other classifiers. In the end, the article concluded that human resource management (HRM) has been overcome this challenge.

Classification methods has been used to estimate the turnover of employees and evaluating the number of attritions [17]. They took three mining algorithms Naïve Bayes, J48 (C4.5), and Random Tree, respectively. The authors analyzed the Employees attrition rate by classifying the data into two labels "Yes" and "No". the "Yes" label clarified the employees who leave the organization and the" No" label illustrated the employee's continuity in the organization. The research concluded that the percentage of employees leaving companies is $20.70 \%$ by Naïve Bayes, $31 \%$ by J48, and $100 \%$ by Random Tree. The retention ratio is $79.3 \%$ by Naïve Bayes, $69 \%$ by J48, and $0 \%$ by random tree. According to their assumption, the Naïve region performs better rather than two other algorithms.

As in [18],[19] the researchers proposed a classification model to find out the factor affecting employee 
turnover. A predictive decision tree has been used. Their model has been used R language Environment to build the model. The proposed model used the c5.0 algorithm, decision tree algorithm, and Rap algorithm to determine these factors. This proposed model proofed that continuous communications between the employee and their managers might reduce the turnover problem. Table 1 illustrates a summary of related data mining algorithms which has been used in this paper's literature review.

Table 1. A summary of the datamining algorithms used in the previously related work

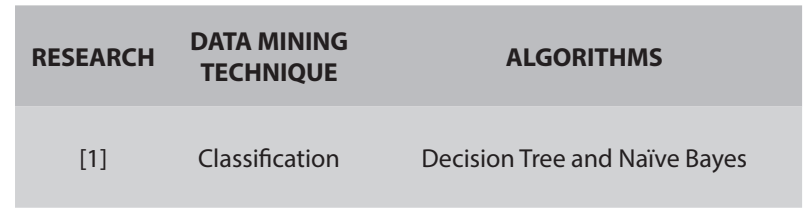

[2] Classification Naive Bayes, decision trees and SVM.

[3] Classification Neural network

[4] Classification Random tree, naive Bayes, J48.

[5] Classification Random forest, decision tree

\section{PROPOSED METHODOLOGY}

The proposed framework can be divided into three phases input, processing and output, respectively. The Specification of the framework is as follows:

\section{- Phase1: Input}

At first, the IT department collects the dataset which provides behavioral, demographic and attitudinal to help you predict Employee turnover according to HR department guidelines. Organization is concerned about the number of workers leaving their company for their rivals. The data are then put into another level which is the preprocessing where data is transformed and cleaned in such a way as that enables it to be used.

\section{- Phase2: Processing}

In this phase Data Mining algorithms will be tested to find out the optimal algorithm for prediction. Using these algorithms, the prediction model discovers hidden features from the collected datasets. Finally, the proposed model performs a comparison between the discovered features and determines which one affects the process of employee turnover.

\section{- Phase3: Output}

The output from the framework can be viewed as the way the result can be visualized to the decision- makers who are the practitioners in a form of, Reports and allows them to make the right decision at the right time. (Fig.1)shows the proposed framework.

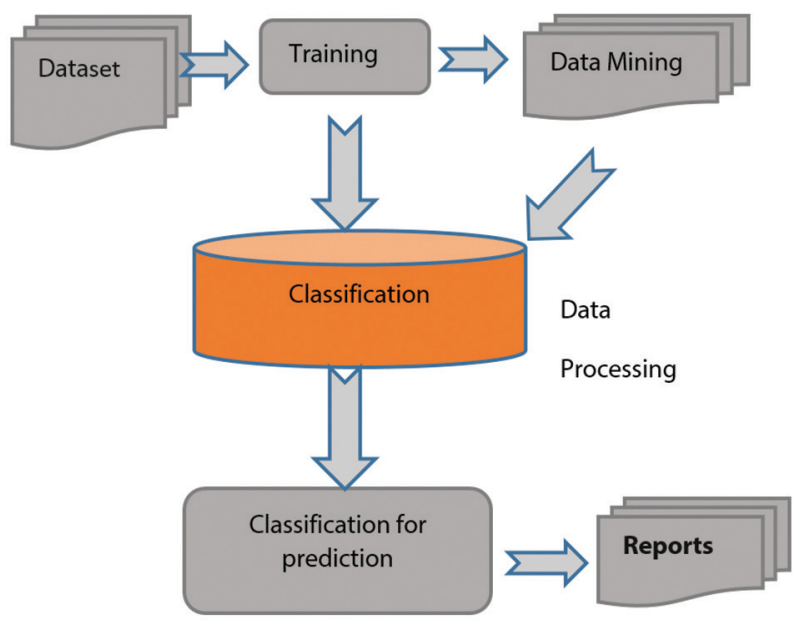

Fig. 1. The proposed framework

\section{CASE STUDY}

This study aims to create a model for predicting the turnover of employees using data mining techniques, in pursuit of a strong solution that can help and support decision-makers in organizations, so that they can make the right decisions when necessary, which helps to reduce the turnover rate and reduce it. Recognizing the turnover before making the necessary precautions and decisions to retain employees contributes effectively to increasing the organization's profit rate.

\section{- Data selection and pre-processing}

The first step in this model is data selection and cleaning.

In this step, we utilize to predict employee attrition by using the HR Employee Attrition dataset provided by IBM. Table 2 illustrates a brief summary of the dataset features. The dataset contains employee information, the factors on which the Employee turnover depends upon are: Behavioral such as:

- Years at Company

- OverTime

- Performance Rating

- Years since Last Promotion

- Total Working Years

Demographics such as:

- Age

- Monthly Income

- Distance from Home

- Marital Status

- Education

- Gender

Attitudinal such as:

- Environment Satisfaction

- Job Satisfaction

- Work-Life Balance

- Number of Companies Worked 
Table 2. The dataset features description

\begin{tabular}{|c|c|}
\hline Attribute & Values \\
\hline Age & 18 To 60 \\
\hline Daily Rate & 102 To 1499 \\
\hline Distance from Home & 1 To 29 \\
\hline Hourly Rate & 30 To 100 \\
\hline Monthly Income & 1009 To 19973 \\
\hline Monthly Rate & 2044 To 26999 \\
\hline Number of Companies Worked & 0 To 9 \\
\hline Percent Salary Hike & 11 To 25 \\
\hline Total Working Years & 0 To 40 \\
\hline Training Times Last Year & 0 To 6 \\
\hline Years at Company & 0 To 36 \\
\hline Years in Current Role & 0 To 17 \\
\hline Years since Last Promotion & 0 To 15 \\
\hline Years with Current Manager & 0 To 17 \\
\hline Department & $\begin{array}{l}\text { H.R, Research \&Development, } \\
\text { Sales, IT }\end{array}$ \\
\hline Education & 1 To 5 \\
\hline Gender & Male, Female \\
\hline Environment Satisfaction & 1Тo 4 \\
\hline Job Involvement & 1 To 4 \\
\hline Job Level & 1 To 5 \\
\hline Job Role & $\begin{array}{l}\text { Manager, Sales Executive, } \\
\text { Laboratory Technician, Research } \\
\text { Director, Human Recourses, } \\
\text { Healthcare Representative, } \\
\text { Manufacturing Director. }\end{array}$ \\
\hline Job Satisfaction & 1 To 4 \\
\hline Marital Status & Single, Married, Divorced \\
\hline Over Time & Yes, No \\
\hline Performance Rating & 3,4 \\
\hline Work Life Balance & 1 To 4 \\
\hline Relationship Satisfaction & 1 To 4 \\
\hline
\end{tabular}

\section{- Classification}

It is the task of data analysis, that is, the process of finding the model that represents and characterizes layers and concepts of the data [6]. Classification is the question of defining each class category based on the data set of training that includes notes and determines class membership.

Classification depends on machine learning, where each entity is categorized into one of a predefined set of categories or groups within a collection of data The system is built in such a way that data classification data elements into groups. The classification, for example, can be extended to records of workers who have left the firm, In this case, the employee records are divided into two categories called "leave" and "the rest," and then the Data
Mining techniques will identify the employees into those two predefined classes. Various algorithms were used to test the data. The Generalized Linear Model, Deep learning, Logistic Regression, logistic slope, and support vector machine. In this research, the test was carried out by applying a set of classification algorithms such as logistic regression, random forest, Fast Large Margin, Gradient Boosted Trees. These algorithms were implemented through data mining software (Rapid Miner).

\section{- Prediction}

Prediction or expectation of Data Mining techniques that expose the relationship between independent and non-independent variables; In other words, if we want to use sales forecasting approaches to estimate future earnings, if we find revenue to be an independent variable, then that may be a dependent variable. Prediction is similar to classification, except that we are trying to predict the value of a numerical variable (e.g., amount of purchase) rather than a class (e.g. Purchaser or no purchaser). Of course, in classification, we seek to forecast a class, but the term prediction refers to forecast the value of a continuous variable [7].

\section{RESULTS}

In this part, we have used classification algorithms to know the most suitable algorithms in the process of predicting employee turnover, and the most influential algorithms have been monitored that have achieved the highest percentage of accuracy such as:

Generalized Linear Model Achieved accuracy by $87.9 \%$, Deep learning Achieved accuracy by $86.2 \%$, Logistic Regression Achieved accuracy by $85.5 \%$, Naive Bayes Achieved accuracy by $85.2 \%$, Gradient Boosted Trees Achieved accuracy by $85 \%$, Random Forest Achieved accuracy by $83.1 \%$, Support Vector Machine Achieved accuracy by $83.1 \% \%$, Fast Large Margin Achieved accuracy by $83.1 \%$. The results have been summarized in figure 2 for all the algorithms used and from the application and the results are summarized. The most appropriate classification algorithms have been known in the prediction process.

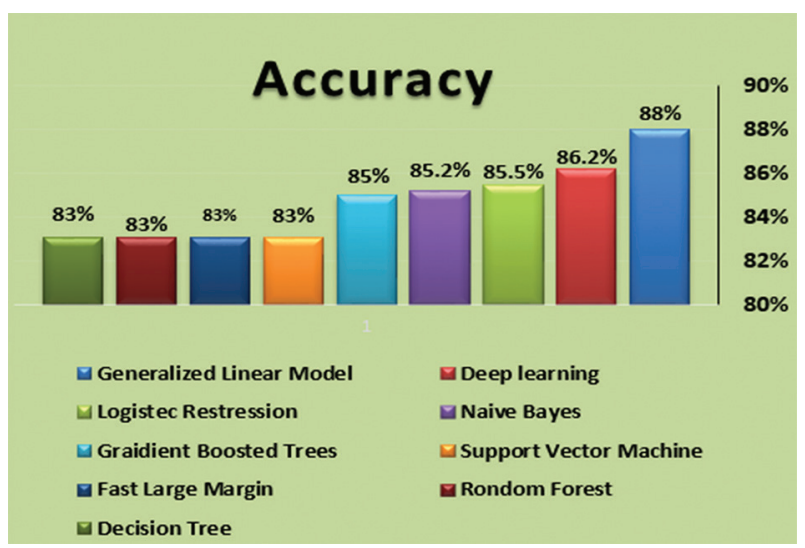

Fig. 2. The classification algorithms accuracy summary 


\section{- Detailed Accuracy}

The accuracy of the details for each algorithm includes precision and Recall and F-measure. Table 3 shows the Detailed Accuracy.

Table 3. Classification algorithms accuracy, precision, recall and F-Measure

\begin{tabular}{|c|c|c|c|c|}
\hline Algorithm & Accuracy & Precision & Recall & F-Measure \\
\hline $\begin{array}{c}\text { Generalized } \\
\text { Linear Model }\end{array}$ & $87.9 \%$ & $88.4 \%$ & $98.3 \%$ & $93.1 \%$ \\
\hline Deep learning & $86.2 \%$ & $85.9 \%$ & $99.7 \%$ & $92.3 \%$ \\
\hline $\begin{array}{c}\text { Logistic } \\
\text { Regression }\end{array}$ & $85.5 \%$ & $85.6 \%$ & $99.5 \%$ & $92.0 \%$ \\
\hline Naive Bayes & $85.2 \%$ & $85.1 \%$ & $99.7 \%$ & $91.8 \%$ \\
\hline $\begin{array}{c}\text { Gradient } \\
\text { Boosted Trees }\end{array}$ & $85 \%$ & $84.9 \%$ & $99.7 \%$ & $91.7 \%$ \\
\hline $\begin{array}{c}\text { Support Vector } \\
\text { Machine }\end{array}$ & $83.1 \%$ & 83.1 & $100 \%$ & $90.8 \%$ \\
\hline $\begin{array}{l}\text { Fast Large } \\
\text { Margin }\end{array}$ & $83.1 \%$ & 83.1 & $100 \%$ & $90.8 \%$ \\
\hline Random Forest & $83.1 \%$ & 83.1 & $100 \%$ & $90.8 \%$ \\
\hline Decision Tree & $83.1 \%$ & $83.4 \%$ & $99.4 \%$ & $90.7 \%$ \\
\hline
\end{tabular}

\section{- Important factors by weights}

This section contains the most important factors affecting the employee turnover process for each algorithm by weight. They are in the order of age, Over Time, Monthly Income, Total Working years, Years At a company as shown in Table 4, Training Time last year, Department, Job Satisfaction, Job involvement, Environment Satisfaction as shown in Table 5 and Stock Option Level, Hourly Rate, Daily Rate, Job Role, Job Level as shown in Table 6.

Table 4. Significant features with weights

\begin{tabular}{|c|c|c|c|c|c|}
\hline \multirow{2}{*}{ Algorithm } & \multicolumn{5}{|c|}{ Weights } \\
\hline & ֻั & 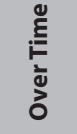 & 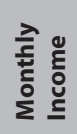 & 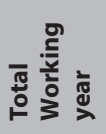 & 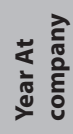 \\
\hline $\begin{array}{l}\text { Generalized } \\
\text { Linear Model }\end{array}$ & 0.152 & 0.619 & 0.073 & 0.038 & 0.003 \\
\hline Deep learning & 0.078 & 0.480 & 0.058 & 0.079 & 0.020 \\
\hline $\begin{array}{l}\text { Logistic } \\
\text { Regression }\end{array}$ & 0.136 & 0.287 & 0.027 & 0.120 & 0.024 \\
\hline Naive Bayes & 0.199 & 0.371 & 0.232 & 0.217 & 0.165 \\
\hline $\begin{array}{l}\text { Gradient } \\
\text { Boosted Trees }\end{array}$ & 0.077 & 0.515 & 0.247 & 0.042 & 0.025 \\
\hline $\begin{array}{c}\text { Support Vector } \\
\text { Machine }\end{array}$ & 0.014 & 0.015 & 0.011 & 0.013 & 0.012 \\
\hline $\begin{array}{l}\text { Fast Large } \\
\text { Margin }\end{array}$ & 0.091 & 0.001 & 0.777 & 0.090 & 0.157 \\
\hline
\end{tabular}

$\begin{array}{cccccc}\text { Random Forest } & 0.150 & 0.085 & 0.288 & 0.039 & 0.145 \\ \text { Decision Tree } & 0.094 & 0.018 & 0.067 & 0.011 & 0.021\end{array}$

\section{- Age}

As shown in table 4 the age is one of the most important factors affecting employee turnover, where the average age of employees is 37 years as shown in the figure., and the higher the employee's age than this average, the less likely the employee will leave work. (Fig.3) illustrates the significant employee age for employee turnover.

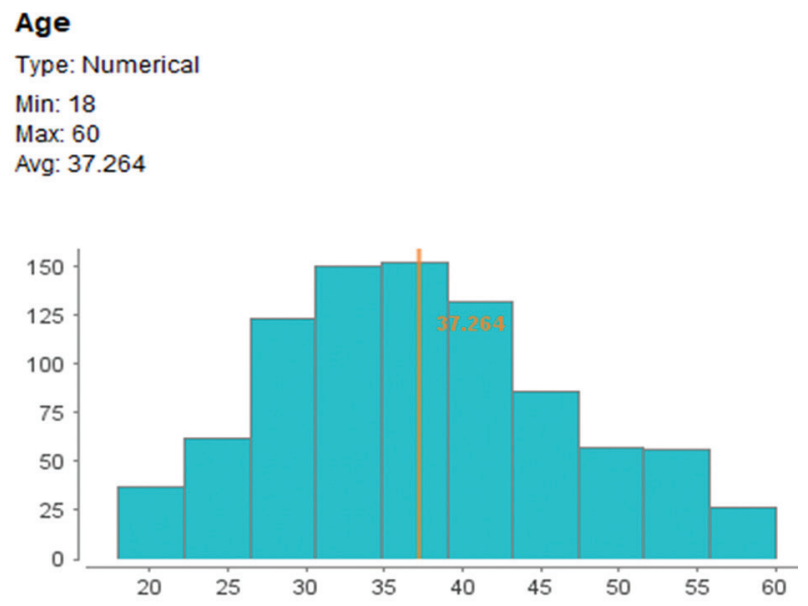

Fig. 3. the significant age for employee turnover

\section{- Overtime}

The more overtime is calculated and added to the employee, the less likely the employee will be left to work. The overtime description is shown in the (Fig.4).

\section{OverTime}

Type: Nominal

Mode: No

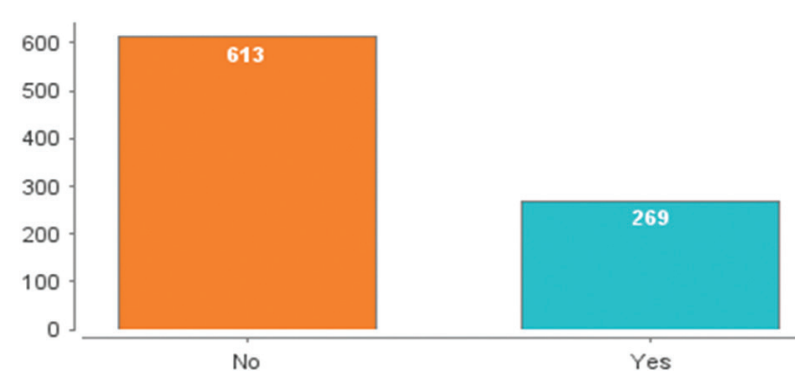

Fig. 4. Overtime impacts in the employee turnover

\section{- Monthly Income}

One of the most important factors affecting employee turnover is the monthly income of an employee. The higher the employee's monthly income, the more likely he will be left to work. Describe the monthly income as shown in the (Fig.5). 


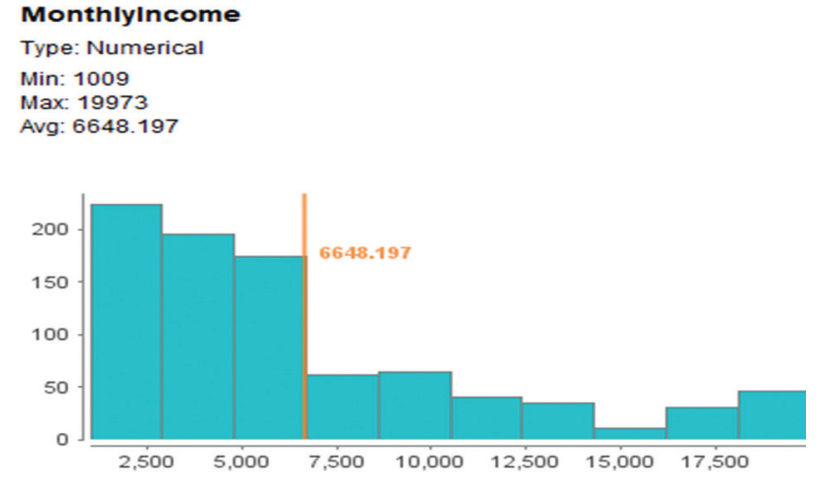

Fig. 5. Monthly Income description

\section{- Total Working year}

Working years is one of the most important factors affecting employee turnover. The more years an employee has worked in the organization, the less likely he will leave. Description of working years as shown in (Fig.6).

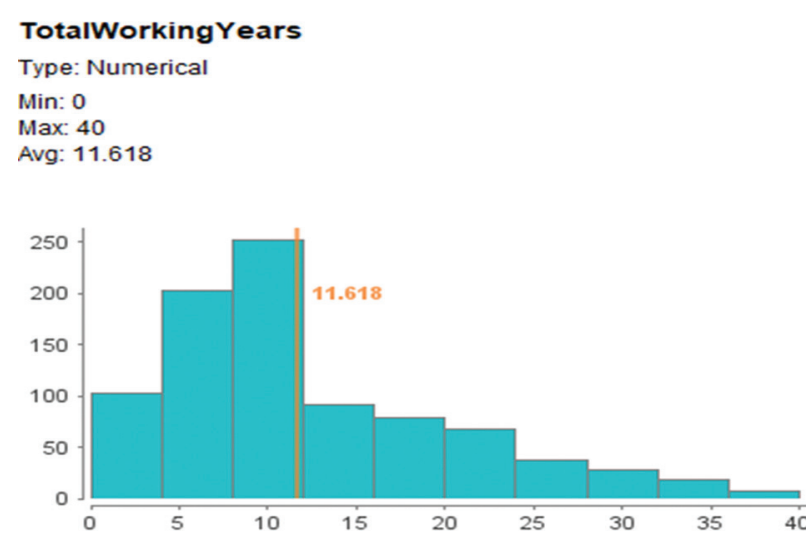

Fig. 6. working years significant value in employee turning over

\section{- Years at a company}

The years in a company are one of the most important factors that affect employee turnover. The average number of years in a company is about 7 years, and the longer the number of years exceeds the expected, the less likely the employee will leave the organization and the description of work years as shown in (Fig.7).

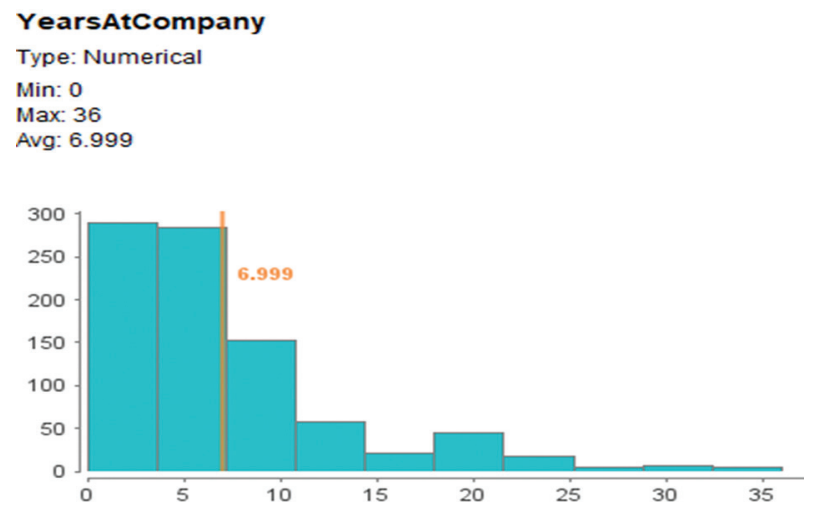

Fig.7. the significant working years at the same company value
Table 5. Significant features with weights

\begin{tabular}{|c|c|c|c|c|c|}
\hline Algorithm & 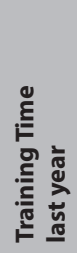 & 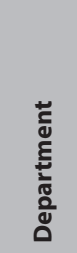 & 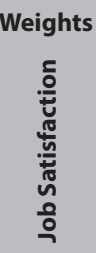 & 응 & 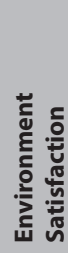 \\
\hline $\begin{array}{l}\text { Generalized } \\
\text { Linear Model }\end{array}$ & 0.161 & 0.105 & 0.135 & 0.101 & 0.146 \\
\hline Deep learning & 0.104 & 0.070 & 0.139 & 0.040 & 0.083 \\
\hline $\begin{array}{c}\text { Logistic } \\
\text { Regression }\end{array}$ & 0.073 & 0.010 & 0.145 & 0.007 & 0.029 \\
\hline Naive Bayes & 0.051 & 0.056 & 0.030 & 0.038 & 0.013 \\
\hline $\begin{array}{c}\text { Gradient } \\
\text { Boosted Trees }\end{array}$ & 0.053 & 0.036 & 0.033 & 0.043 & 0.061 \\
\hline $\begin{array}{l}\text { Support Vector } \\
\text { Machine }\end{array}$ & 0.010 & 0.013 & 0.009 & 0.015 & 0.008 \\
\hline $\begin{array}{c}\text { Fast Large } \\
\text { Margin }\end{array}$ & 0.011 & 0.026 & 0.122 & 0.119 & 0.004 \\
\hline Random Forest & 0.036 & 0.025 & 0.034 & 0.054 & 0.014 \\
\hline Decision Tree & 0.068 & 0.040 & 0.013 & 0.015 & 0.013 \\
\hline
\end{tabular}

\section{- Training time last year}

Continuous employee training increases his skills and efficiency, and therefore, the higher the employee's training, the less likely they are to leave the job. Describe the training times as shown (Fig.8).

\section{Training TimesLastYear}

Type: Numerical

Min: 0

Max: 6

Avg: 2.819

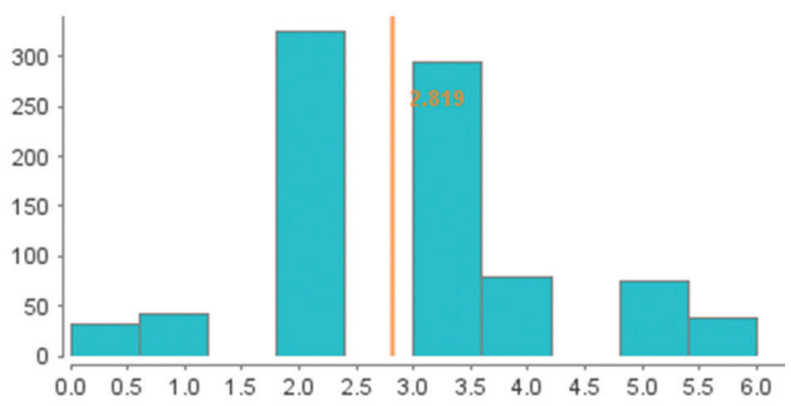

Fig.8. the significant training time last year value

\section{- Departments}

Regarding the departments, the Research and Development Department has the largest number of employees, as shown in the (Fig.9). 


\section{Department}

Type: Nominal

Mode: Research \& Development

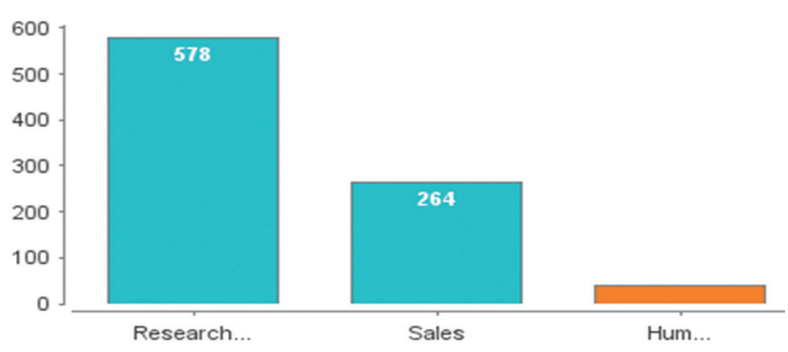

Fig.9. Departments Description

\section{- Job Satisfaction}

Undoubtedly, job satisfaction is one of the most important factors for employees and its job performance. The higher the job satisfaction rate for an employee, the more related to the institution and not leaving it to work. The job Satisfaction description is shown in the (Fig.10).

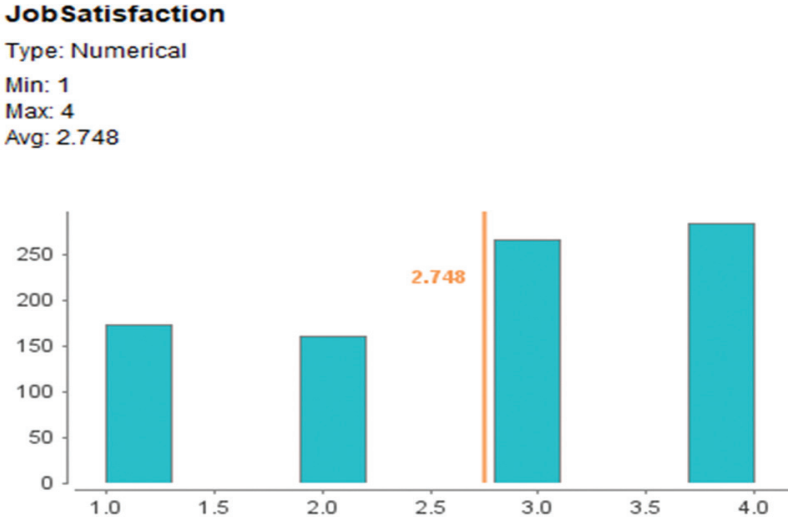

Fig.10. Job Satisfaction significant turnover value

\section{- Job involvement}

Job involvement is one of the most important factors that affect employee turnover, so the higher the employee's job participation rate, the less likely he will leave the job. Job involvement description as shown in the (Fig.11).

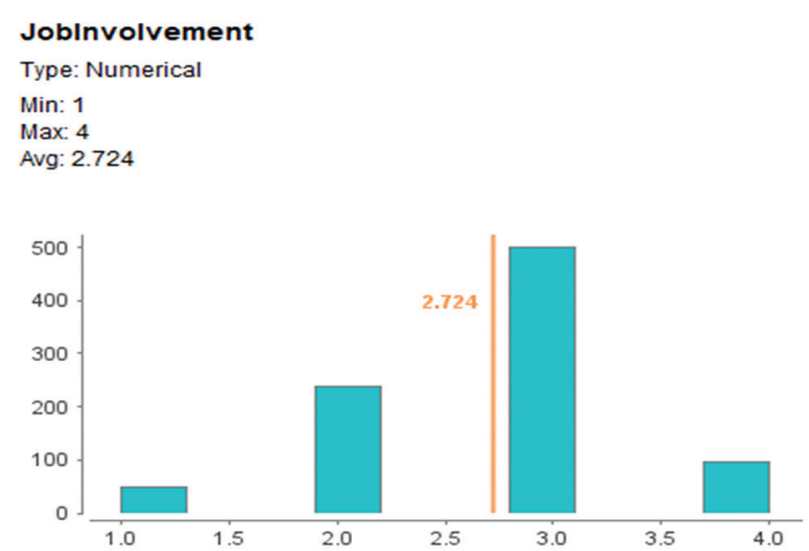

Fig.11. Job involvement significant employee turnover value

\section{- Environment Satisfaction}

The higher the degree of satisfaction with the work environment in terms of capabilities and workplace, the more employee is attached to the organization and a difficult legacy of work. Add satisfaction to the environment shown in (Fig.12).

\section{EnvironmentSatisfaction}

Type: Numerical

Min: 1

Max: 4

Avg: 2.737

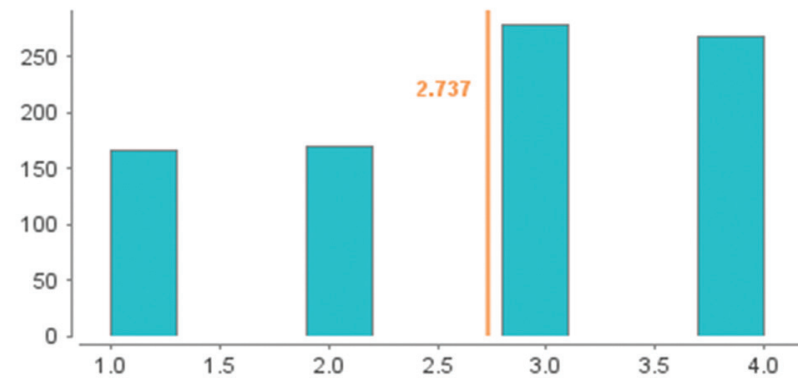

Fig.12. Environmental Satisfaction histogram

Table 6. Significant features with weights

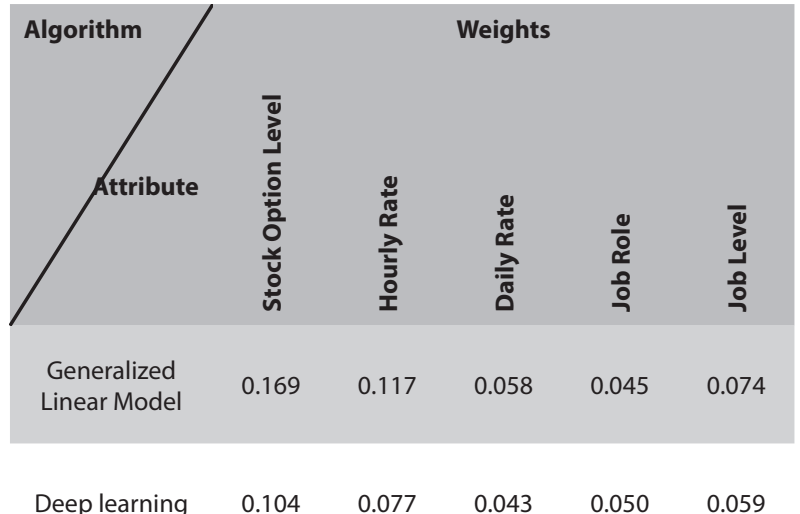

\begin{tabular}{llllll} 
Logistic & 0.087 & 0.051 & 0.002 & 0.069 & 0.022 \\
Regression & & & & & \\
\hline
\end{tabular}

$\begin{array}{llllll}\text { Naive Bayes } & 0.119 & 0.053 & 0.034 & 0.069 & 0.102\end{array}$

$\begin{array}{cccccc}\begin{array}{c}\text { Gradient } \\ \text { Boosted Trees }\end{array} & 0.123 & 0.052 & 0.009 & 0.059 & 0.055\end{array}$

$\begin{array}{llllll}\text { Support Vector } & 0.013 & 0.010 & 0.012 & 0.012 & 0.015\end{array}$
Machine

$\begin{array}{llllll}\begin{array}{l}\text { Fast Large } \\ \text { Margin }\end{array} & 0.004 & 0.180 & 0.001 & 0.002 & 0.011\end{array}$

$\begin{array}{llllll}\text { Random Forest } & 0.057 & 0.035 & 0.102 & 0.039 & 0.040\end{array}$

$\begin{array}{llllll}\text { Decision Tree } & 0.032 & 0.070 & 0.056 & 0.025 & 0.019\end{array}$ 


\section{- $\quad$ Stock Option Level}

The stock option level contains values 1 to 3 , on average 0.755 .As shown in the (Fig.13).

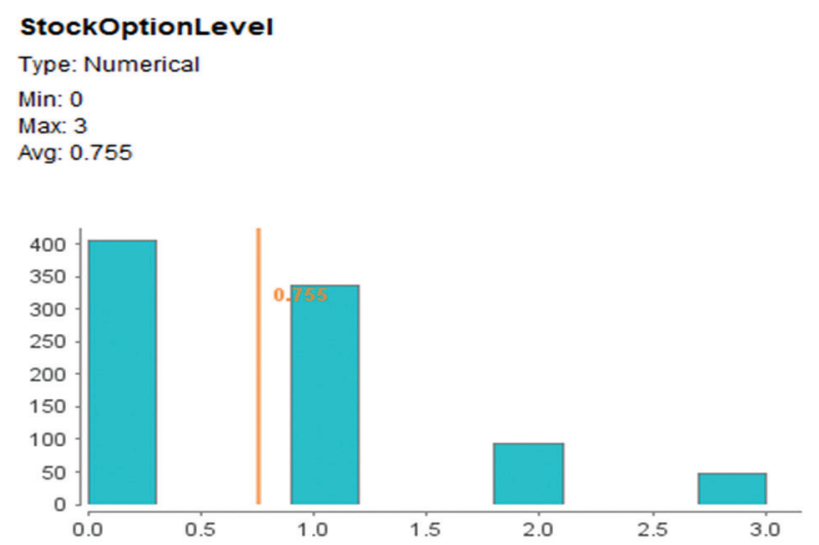

Fig.13. Stock option level significant value for employee turnover

\section{- Hourly Rate}

The Hourly rate contains values 30 to 100 , on average 65.5. As shown in (Fig.14).

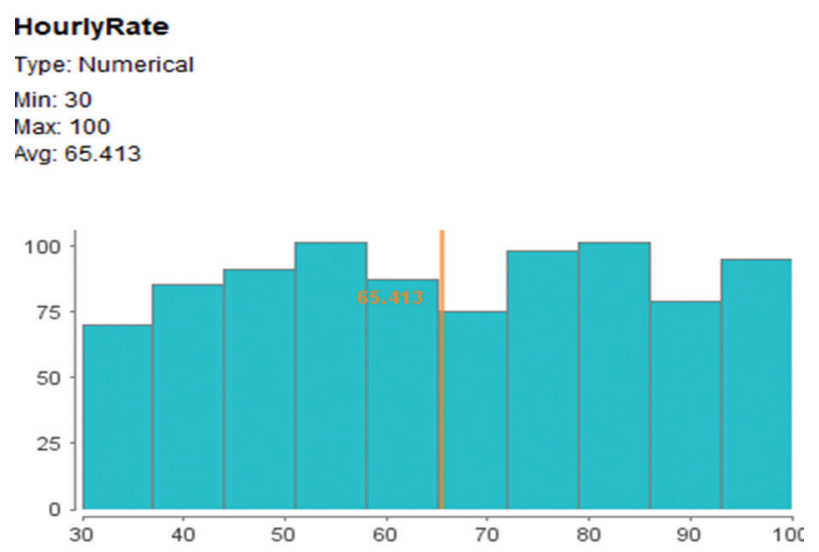

Fig.14. Hourly Rate histogram

\section{- Daily Rate}

The Daily rate contains values 102 to 1499 , on average 799. As shown in (Fig.15).

\section{DailyRate}

Type: Numerical

Min: 102

Max: 1499

Avg: 795.026

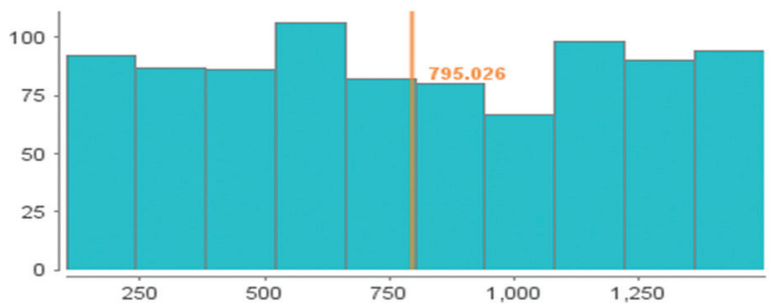

Fig.15. daily rate histogram

\section{- Job Role}

Job roles contain a range of roles such as Sales Director, Laboratory Technician Research Director (Fig.16) illustrates a description of the job roles.

\section{JobRole}

Type: Nominal

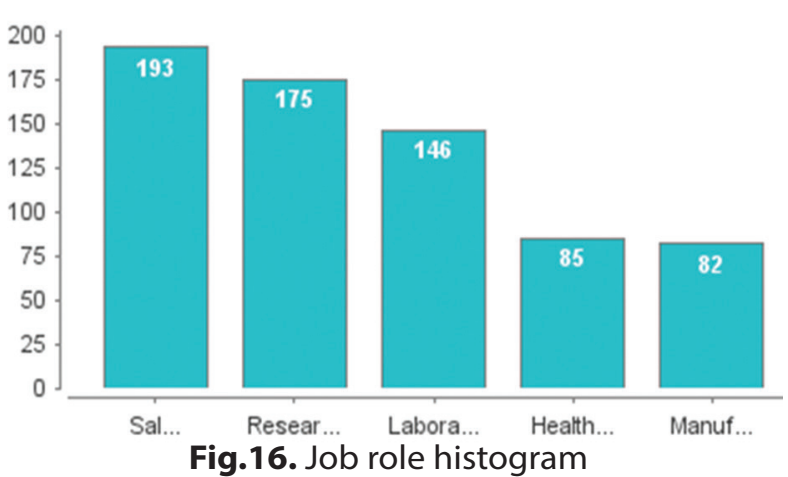

\section{- Job Level}

The job level contains values 1 to 5 , on average 2.09. As shown in the (Fig.17).The higher the employee's career level, the less likely the employee is to leave work.

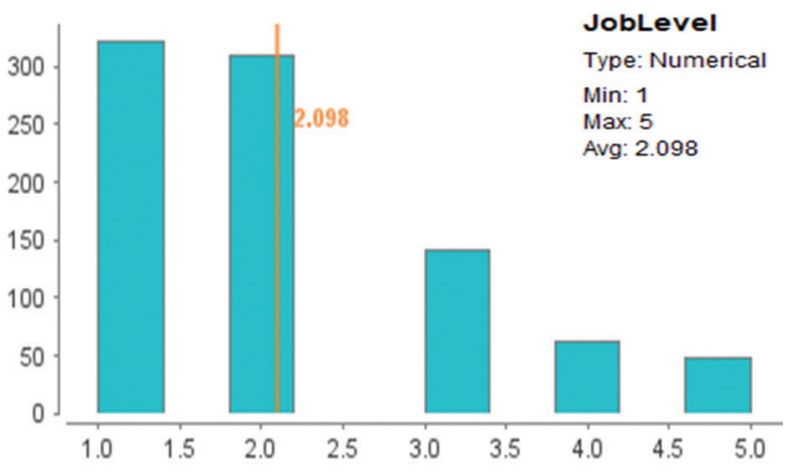

Fig.17. Job level histogram

\section{CONCLUSION}

This paper proposes a case study for predicting employee turnover features using data mining techniques that have effectively contributed to the accuracy of expected employee turnover. The proposed model performs classification using some of the well-known benchmark algorithms such as support vector machine, decision tree, linear regression, random forest, and deep learning with an average accuracy rate of $88 \%$. Also, the model defines the most important factors affecting employee turnover according to its significant weights. Demographic features such as Age, Monthly Income and behavioral features such as Over Time, Years at Company, Total Working Years and attitudinal factors such as Environment Satisfaction, Job Satisfaction have been found as the most significant factors affecting employee turnover. 


\section{REFERENCES}

[1] Q. A. Al-Radaideh, E. Al Nagi, "Using data mining techniques to build a classification model for predicting employee's performance", International Journal of Advanced Computer Science and Applications, Vol. 3, No. 2, 2015, pp. 144-151.

[2] A. Sikaroudi, S. Rouzbehghousi, A. Esmaieelisikaroudi, "A Data Mining Approach To Employee Turnover Prediction (Case Study: Arak Automotive Parts Manufacturing)", Journal Of Industrial And Systems Engineering, Vol. 8, No. 4, 2016, pp. 106-121.

[3] R. Punnoose, P. Ajit, "Prediction Of Employee Turnover In Organizations Using Machine Learning Algorithms", International Journal Of Advanced Research In Artificial Intelligence, Vol. 5, No. 9, 2016, pp. 20-27.

[4] P. S. Devi, B. Umadevi, "A Novel Approach to Control the Employee's Attrition Rate of an Organization", International Journal of Computer Science and Mobile Applications, Vol. 6, No. 7, 2018, pp.43-52.

[5] L. Girmanova, Z. Gašparová, "Analysis of Data on Staff Turnover Using Association Rules and Predictive Techniques", Quality Innovation Prosperity, Vol. 22, No. 2, 2018, pp. 82-99.

[6] Y. Helmy, A. E. Khedr, S. Kolief, E. Haggag, "An Enhanced Business Intelligence Approach for Increasing Customer Satisfaction Using Mining Techniques", International Journal of Computer Science and Information Security, Vol. 17, No. 4, 2019, pp. 159-176.

[7] A. E. Khedr, J. N. Kok, "Adopting Knowledge Discovery In Databases for Customer Relationship Management in Egyptian Public Banks", Proceedings of the International Conference on Professional Practice in Artificial Intelligence, Santiago, Chile, 21-24 August 2006, pp. 201-208.

[8] A. M. Mostafa, A. E. Khedr, A Abdo, "Advising Approach to Enhance Students' Performance Level in Higher Education Environments", Journal of Computer Science, Vol. 13, No. 5, 2017, pp. 130-139.

[9] K. K. Tsiptsis, A. Chorianopoulos, "Data mining techniques in CRM: inside customer segmentation", John Wiley \& Sons, 2011.
[10] C. A. Al Mamun, M. N. Hasan, "Factors affecting employee turnover and sound retention strategies in business organization: a conceptual view", Problems and Perspectives in Management, Vol. 15, No. 1, 2017, pp. 63-71.

[11] R. Mendes, J. P. Vilela, "Privacy-preserving data mining: methods, metrics, and applications," IEEE Access, Vol. 5, 2017, pp. 10562-10582.

[12] R. B. Palepu, R. R. Muley, "Analysis of agriculture data using data mining techniques: application of big data", Journal of Big Data, Vol. 4, No. 20, 2017.

[13] M. M. Nazier, A. E. Khedr, M. Haggag, "Business Intelligence and its role to Enhance Corporate Performance Management", International Journal of Management \& Information Technology, Vol. 3, No. 3, 2013, pp. 8-15.

[14] G. Shmueli, G. Shmueli, P. C. Bruce, I. Yahav, N. R. Patel, K. Lichtendahl Jr, "Data mining for business analytics: concepts, techniques, and applications in R", John Wiley \& Sons, 2017.

[15] A. E. Khedr, A. M. Idrees, "Adapting Load Balancing Techniques for Improving the Performance of e-Learning Educational Process", Journal of Computers, Vol. 12, No. 3, 2017, pp. 250-257.

[16] S. Rajendran, W. Meert, D. Giustiniano, V. Lenders, S. Polin, "Deep learning models for wireless signal classification with distributed low-cost spectrum sensors", IEEE Transactions on Cognitive Communications and Networking, Vol. 4, No. 3, 2018 pp. 433-445.

[17] A. Khedr, S. Kholeif, F. Saad, "An Integrated Business Intelligence Framework for Healthcare Analytics", International Journal of Advanced Research in Computer Science and Software Engineering, Vol. 7, No. 5, 2017, pp. 263-270.

[18] S. Rajeswari, K. Suthendran. "C5.0: Advanced Decision Tree (ADT) classification model for agricultural data analysis on cloud", Computers and Electronics in Agriculture, Vol. 156, 2019, pp. 530-539.

[19] N Sultan, A. E. Khedr, A Idrees, S Kholeif, "Data Mining Approach for Detecting Key Performance Indicators", Journal of Artificial Intelligence, Vol. 10, No. 2, 2017, pp. 59-65. 